12

\title{
Stochastic Coordination of Joint Wind and Photovoltaic Systems with Energy Storage in Day-Ahead Market
}

\author{
I.L.R. Gomes ${ }^{\mathrm{a}, \mathrm{b}}$, H.M.I. Pousinho ${ }^{\mathrm{a}, \mathrm{b}}$, R. Melício ${ }^{\mathrm{a}, \mathrm{b}, *}$, V.M.F. Mendes ${ }^{\mathrm{b}, \mathrm{c}}$ \\ ${ }^{a} I D M E C$, Instituto Superior Técnico, Universidade de Lisboa, Lisbon, Portugal \\ ${ }^{\mathrm{b}}$ Departamento de Física, Escola de Ciências e Tecnologia, Universidade de Évora, Portugal \\ ${ }^{\mathrm{c}}$ Department of Electrical Engineering and Automation, Instituto Superior de Engenharia de Lisboa, Lisbon, Portugal \\ Received 29 June 2016
}

\begin{abstract}
This paper presents an optimal bid submission in a day-ahead electricity market for the problem of joint operation of wind with photovoltaic power systems having an energy storage device. Uncertainty not only due to the electricity market price, but also due to wind and photovoltaic powers is one of the main characteristics of this submission. The problem is formulated as a two-stage stochastic programming problem. The optimal bids and the energy flow in the batteries are the first-stage variables and the energy deviation is the second stage variable of the problem. Energy storage is a way to harness renewable energy conversion, allowing the store and discharge of energy at conveniently market prices. A case study with data from the Iberian day-ahead electricity market is presented and a comparison between joint and disjoint operations is discussed.

(C) 2016 Elsevier Ltd. All rights reserved.
\end{abstract}

Keywords: Joint operation; day-ahead market; energy storage; PV power; stochastic linear programming; wind power.

\section{Introduction}

Many of once regulated electricity market are restructured in order to allow competition, for instance, over the past few decades many of once regulated electricity markets of European countries went through a restructured procedure to allow competition among market participants [1]. Electricity markets are becoming more competitive with the increase of new market players coming from other sectors to the power industry attracted by the ability of realizing beneficial profits. This is an outcome of incentives provided to renewable energy exploitation, namely variable renewable energy sources like wind and photovoltaic powers. But, incentives tend to be diminishing as parity tends to be achieved. Fossil-fuels sources are characterized not only by being a scarce source of energy, but also by energy conversion with negative impact on the habitat due to the anthropogenic gas emission [2]. So, fossil-fuels sources are not appropriated for a sustainable development. While, renewable energy sources such as wind power or photovoltaic (PV) power are considered to be environmental friendly. Hence, renewable energy has been on increase and is expected to be on increase.

\footnotetext{
* Corresponding author. Tel.: +351 266 745372; fax: +351 266745394 .

E-mail address: ruimelicio@gmail.com (R. Melício).
} 


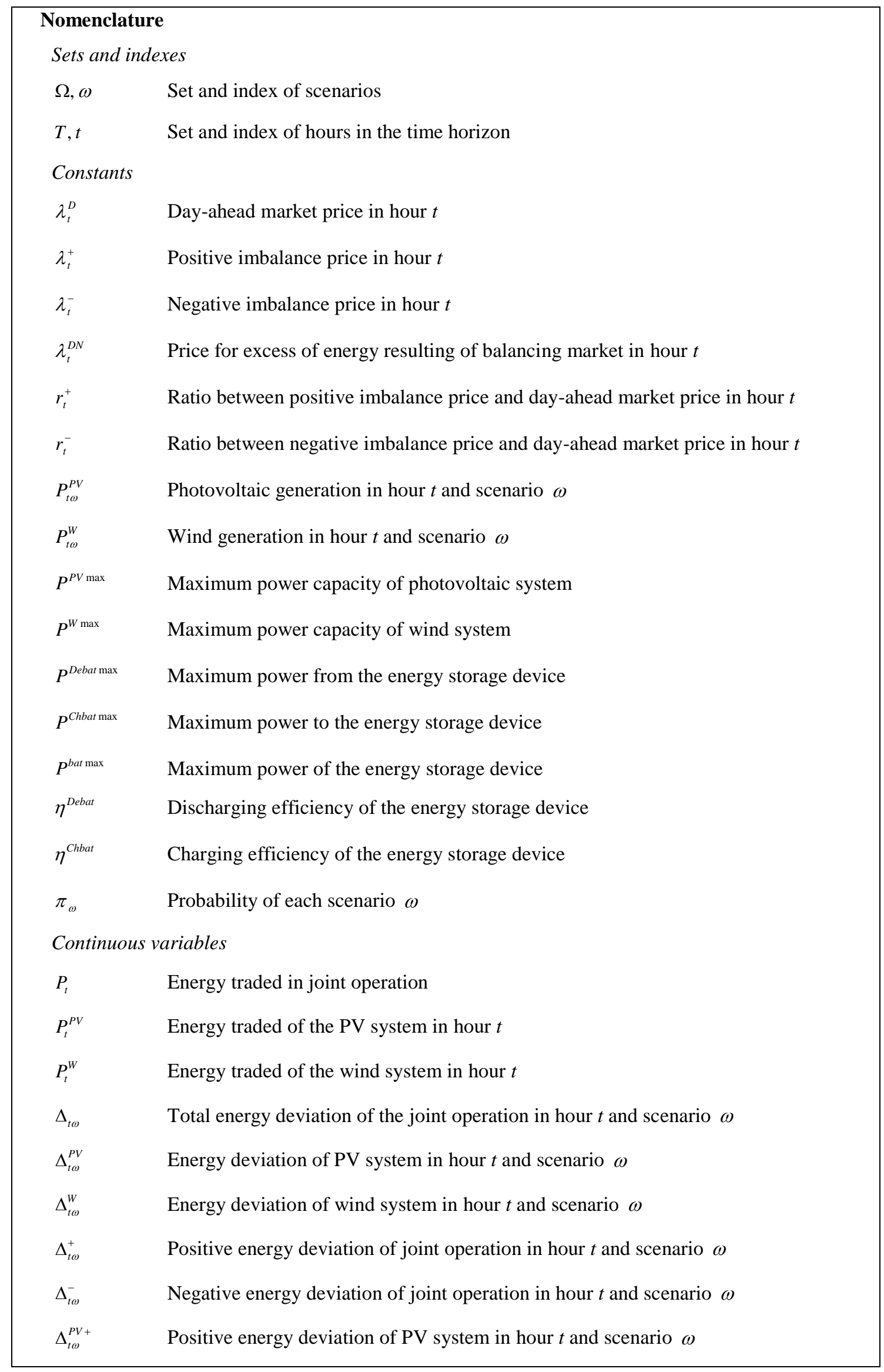




\begin{tabular}{|ll}
\hline$\Delta_{t \omega}^{P V-}$ & Negative energy deviation of PV system in hour $t$ and scenario $\omega$ \\
$\Delta_{t \omega}^{W+}$ & Positive energy deviation of wind system in hour $t$ and scenario $\omega$ \\
$\Delta_{t \omega}^{W-}$ & Negative energy deviation of wind system in hour $t$ and scenario $\omega$ \\
$E_{t}^{\text {bat }}$ & Amount of energy stored in the energy storage device in hour $t$ \\
$P_{t}^{\text {Debat }}$ & Power from the energy storage device in hour $t$ \\
$P_{t}^{C h b a t}$ & Power to the energy storage device in hour $t$ \\
Binary variables & 0/1 variable, equal to 1 for positive energy deviation in hour $t$, otherwise it is 0 for \\
$u_{t \omega}$ & negative energy deviation for joint operation \\
& 0/1 variable, equal to 1 for positive energy deviation in hour $t$, otherwise it is 0 for \\
$u_{t \omega}^{P V}$ & negative energy deviation for PV system \\
0/1 variable, equal to 1 for positive energy deviation in hour $t$, otherwise it is 0 for & negative energy deviation for wind system \\
& o/1 variable, equal to 1 if the energy storage device is charging in hour $t$, otherwise it \\
$u_{t \omega}^{W}$ & is 0 if the energy storage is discharging \\
$k_{t}$ &
\end{tabular}

1

2

Nowadays, distributed power generation systems is a fact, for instances, exploitation of: solar energy by photovoltaic (PV), concentrator solar and integrated solar combined cycle systems; wind energy onshore or offshore by wind turbines $[3,4]$. One of the greatest challenges of many low-carbon generation technology is the lack of a similar level of flexibility for energy-following in comparison with conventional fossil-fuel based power generation. For instances, like wind and PV powers due to the intermittent and variable energy source often unpredictable $[5,6]$.

In 2014, wind power and PV power continue to grow and taking the lead for capacity additions between the renewables [7]. At least 164 countries had renewable energy targets and an estimated 145 countries had renewable energy support policies in place by the end of 2014 [8]. Feed-in-tariffs, guaranteed grid access, green certificates, investments incentives, tax credits and soft balancing costs have been adopted in many countries as incentives for renewable energy exploitation [9]. But as integration of renewable energy increases and grid parity is achieved, the support policies are political unsustainable. So, sooner or later, a power producer with energy conversion from renewable energy into electric energy has to face the competition of a day-ahead electricity market. 
1 PV power systems are best recommended for decentralized electric energy sources. For instance, PV 2 power systems are hailed for energy operation of residential appliances with or without the use of storage 3 batteries [10]. Energy storage is pointed out as the key to the large integration of wind and PV power 4 systems. A report of the National Renewable Energy Laboratory states that the challenges associated with meeting the variation in demand while providing reliable services has motivated historical development of energy storage and that large penetrations of variable generation increases the need of flexibility options [11]. Large scale renewable energy sources integration without energy storage will be a challenge for future power systems [12]. A study regarding intermittent renewable power production from wind and

9 PV powers at Europe states that is required significant backup generation to cover the power demand at all times even if wind and PV powers covers on average $100 \%$ of the demand. Without grid connection,

11 i.e., an autonomous power system, is needed storage backup generation of $40 \%$ of the demand, even with an ideal grid is needed storage backup generation of $20 \%$ [13]. Storage technology could play a vital role in improving the overall stability and reliability of power system and could reduce the costs to improve transmission and distribution capacity to meet the ever growing power demand. Also, storage technology could play an important role in the actual deregulated markets like providing arbitrage, increasing the value of renewable power in markets [14]. In a grid-connected PV power plant, the use of an energy storage device can truly enable the power system to fully meet the power demand and increase the reliability of the power system [15]. Vanadium redox flow batteries is viewed as one of the most promising storage technology for application at power plants, namely to compensate the fluctuations of wind and photovoltaic power plants [16].

A power producer in a day-ahead electricity market has to submit bids at day d-1 for the 24 hours of day $\mathrm{d}$. The closing of the day-ahead electricity market defines power and price for the physical delivery contracts. A management of a fossil-fuel or a conventional power has to face the uncertainty due to electricity price in a day-ahead electricity market. While a wind power or PV power management has to face augmented uncertainty, due to not only electricity price, but also wind power or photovoltaic power, uncertainties. This augmented uncertainty has to be faced in order to cope with physical delivery as much as possible, i.e., with the one having conformity with power contracts $[17,18]$. Otherwise, if different physical delivering than the one having conformity, then economic penalization is due to happen [19]. So, 
1 managed with the aim of best bidding featuring the eventual penalties for energy imbalance [19,20].

2 Consequently, the management of the operation has to deal with the risk of imbalances, i.e., with risk of

3 incurring in penalties due to imbalances. A point of view about a wind power system is the propensity for

4 high availability of the wind energy source at night and particular in the winter time. But a wind power

5 system standing alone is non-capable of ensuring satisfaction of a demand due to the uncertainty on

6 values of the wind speed during operation [21]. Management of wind power has a beneficially treated in

7 the context of stochastic optimization to take into consideration the eventual uncertainty, even when in

8 coordination with hydro power [22,23]. A point of view about PV power system standing alone is the

9 non-capability of providing for a continuous source of energy due to the low availability of the source of

10 energy at non-sun times or in the winter time. The merging of these two points of view bring up a line of

11 enquire about if wind power joint with PV power (Wind-PV) has a better economic revenue for bidding

12 in a day-ahead electricity market. This revenue seems to be likely to happen, because of the mismatch of

13 the non-capabilities from one power system to the other power system. Moreover, joint operation to

14 overcome the uncertain of renewable energy sources impact in energy delivering has been recommended

15 to deal with the eventual imbalance cost [24]. Hence, a research contribution taking advantage of the

16 above mismatch in order to mitigate the impact of uncertainty and variability of the sources of energy in a

17 coordinated bidding is needed and this paper proposes one way for asserting the value of this bidding.

18 A correlation between wind and PV powers has been verified on the Iberian Peninsula, encouraging

19 the joint operation of wind power with PV power to mitigate energy supply uncertainty [25]. The

20 literature presents different approaches of wind bidding strategies to deal with the wind power

21 uncertainty. Wind power producers have the opportunity of combine wind power with energy storage technology, namely pump-storage facilities and compressed air facilities and vanadium redox flow batteries [26-28]. Stochastic nonlinear programming is an approach proposed for bidding strategy with the aim of minimizing the imbalance costs [29]. The use of purchase call/put options to pumped-storage facility is proposed for wind producers to hedge against wind uncertainty [30]. The development of bidding strategy for a wind power owner using deterministic MILP is another approach proposed for the optimal operation [31,32]. This paper is a research contribution for aiding a power producer owning a wind system, a PV system and an energy storage device in order to establish a beneficial single bid in a day-ahead electricity market, using a stochastic approach based in MILP. 


\section{Problem Description}

A power producer owning a wind system and a PV system, i.e., Wind-PV producer, faces augmented 4 uncertainty established by the availability of the sources of energy, wind velocity and solar irradiance.

5 This augmented uncertainty, due to the intermittence and variability of wind power and solar irradiance is 6 in addition to the uncertainty on the closing price of the day-ahead market. Thus, the market strategy for a

7 Wind-PV producer must take into account a convenient addressment of these uncertainties in order to 8 capture the most as possible of revenue from the trading of energy in a day-head electricity market.

9 Otherwise, if not conveniently addressed, then eventual losses on revenue occur due to a not conveniently

10 treatment of imbalance penalty economic impact. A convenient addressment of the uncertainties can 11 mitigate the eventual negative impact on the revenue of the Wind-PV producer in comparison with a 12 disjoint operation of wind with PV powers.

\subsection{Imbalance prices}

14 A system imbalance in hour $t$ or a global imbalance in hour $t$, i.e., an imbalance in the whole power system, is defined as a non-null difference in hour $t$ between the sum of level of the physical delivering of energy for all producers with bids accepted at the closing of the day-ahead market and the demand for energy. A producer imbalance in hour $t$, i.e., a local imbalance in the power system in hour $t$, is defined for a producer as a non-null difference between the level of the physical delivering of energy of the producer and the level of the energy contracted due to the accept bid in hour $t$. The power producer is accountable for accepting a settlement of the market due to the imbalance. For instance, reimbursement due to a negative imbalance given by a price times the absolute value of the quantified negative imbalance. The system imbalance or the producer imbalance may be negative, null or positive, but as long as there is producer imbalance the producer is subjected to a procedure from the day-ahead market. The procedure in the Iberian electricity market is to subject the producer to a price for the positive energy imbalance and another price for negative energy producer imbalance. These prices depend on the sign of the system imbalances in the respective hour. Thus, if the system imbalance is positive, i.e., excess of generation, the power producers with excess of generation has the possibility of sold its excess of generation at a price smaller than the day-ahead market-clearing price. This represents a profit smaller than the profit achieved if the excess of generation was sold in the day-ahead market. The power producers with a deficit of generation, helps to alleviate the excess of generation in the power system, but 
1 is also subject to an imbalance price in the day-ahead market. If the system imbalance is positive the

2 imbalances prices are as follow:

$3 \quad \lambda_{t}^{+}=\min \left(\lambda_{t}^{D}, \lambda_{t}^{D N}\right)$

$4 \quad \lambda_{t}^{-}=\lambda_{t}^{D}$

5 In (1) and (2), $\lambda_{t}^{+}$and $\lambda_{t}^{-}$, are applied in the imbalance market to the positive and negative energy

6 deviations, respectively, $\lambda_{t}^{D}$ is the day-ahead market-clearing price and $\lambda_{t}^{D N}$ is the maximum price of the

7 energy of offers in exceeds of the value accepted by the day-ahead market. Otherwise, if the system

8 imbalance is negative, the prices are as follow:

$9 \lambda_{t}^{+}=\lambda_{t}^{D}$

$10 \quad \lambda_{t}^{-}=\max \left(\lambda_{t}^{D}, \lambda_{t}^{U P}\right)$

11 In (4), $\lambda_{t}^{U P}$ is the minimum price of the energy that needs to be added to the system.

122.2 Power producer revenue in electricity markets

13 Once having the bid accepted, a power producer in hour $t$ has the revenue given as follows:

$14 R_{t}=\lambda_{t}^{D} P_{t}+I_{t}$

15 In (5), $\lambda_{t}^{D}$ is the day-ahead market price, $P_{t}$ is the power contracted at the closing of the day-ahead

16 market, $I_{t}$ is the economic value associated with the imbalance resulting from the physical delivering

17 mismatch and can lead to losses of revenue. The imbalance incurred by the power producer in hour $t$ is

18 given as follows:

$19 \Delta_{t}=P_{t \omega}-P_{t}$

20 where $P_{t \omega}$ is the total actual power associated with the physical delivering of energy in hour $t . I_{t}$ is given

21 as follows:

$22 I_{t}=\lambda_{t}^{+} \Delta_{t}, \Delta_{t} \geq 0$

$23 I_{t}=\lambda_{t}^{-} \Delta_{t}, \Delta_{t}<0$

24 In (7), $\lambda_{t}^{+}$is the price at which the power producer will be paid for the excess of generation and in (8)

$25 \lambda_{t}^{-}$is the price to be charged for the deficit of generation. A positive imbalance, i.e., the physical energy 
1 delivering is not less than the contracted one, is associated with a positive imbalance price ratio never

2 greater than one. The positive imbalance price ratio is defined as follows:

$3 \quad r_{t}^{+}=\frac{\lambda_{t}^{+}}{\lambda_{t}^{D}}, r_{t}^{+} \leq 1$

4 A negative imbalance is associated with a negative imbalance price ratio never less than one. The 5 negative imbalance price ratio is defined as follows:

$6 \quad r_{t}^{-}=\frac{\lambda_{t}^{-}}{\lambda_{t}^{D}}, r_{t}^{-} \geq 1$

7 The imbalance in hour $t$ can be written in function of the price of the day-ahead market and of the above

8 ratios in hour $t$ by substitution of (9) and (10) into (7) and (8), respectively giving the imbalance as 9 follows:

$10 \quad I_{t}=\lambda_{t}^{D} r_{t}^{+} \Delta_{t}, \Delta_{t} \geq 0$

$11 I_{t}=\lambda_{t}^{D} r_{t}^{-} \Delta_{t}, \Delta_{t}<0$

\subsection{Energy balance and unforeseen events}

13 A power producer submits an offer for selling energy in the day-ahead market without knowing the 14 market prices nor even if the offer is accepted. If the offer is accepted, then the energy should be delivered in the next day. But production in order to deliver the energy is subjected to unforeseen events,

16 as for instance, the production is not meeting target expectations due to failure of equipment. Furthermore, if the power producer exploits wind or PV powers, then the producer has further uncertainty due to the nondeterministic availability of these powers. If the energy delivered is different from the level of energy assign to the producer at the closing of the day-head market, then the producer incurs in an imbalance. Particularly, in case of delivering less energy than the one assign at the closing, a loss of profit is due to happen relatively to the profit of a sound offer, i.e., an offer accepted and with non-imbalance delivering in the next day.

The system operator is liable for prearranging through schedule settings the balancing of energy delivered with energy demanded in the system, acting in due time to level delivering with consumption of energy. The imbalance market is the place where to sell or to purchase energy in order to avoid an imbalance due to unforeseen events. Unforeseen events that occur after the close of the day-ahead market are resolved by the trading of energy in the imbalance market, where producers in this market must be 
1 able to go into production quickly when called. An adjustment implies an amount of energy to be traded

2 and thereby has an effect on the positive or negative imbalance prices. Therefore, the consideration of this

3 effect could improve the description of the real market. But, although this paper is not about imbalance

4 markets, the presented approach can be used to diminish the impact of unforeseen events by considering

5 power scenarios suitable to handle those events. So, the proposed approach allows for wind or PV powers

6 backup of one to each other at unforeseen event in order to have a beneficial bid in a day-ahead market.

7 Also, hardware is important to deal with unforeseen events. For instance, for a successful black-start in a

8 wind system due to a sudden disconnection: an auxiliary service, such as a battery storage unit, may be

9 connected at the end of the rectifier in order to supply continuity of charge on the capacitors banks,

10 allowing to achieve a successful black-start [33,34].

\section{3. Proposed Approach}

12 Uncertainty is present in the most of decision-making problems of electricity markets participants, 13 especially in power producers exploiting renewable energy sources, like wind or PV powers. Stochastic 14 programming is a suitable optimization approach to deal with decision-making for problems under 15 uncertainty [35].

$16 \quad 3.1$ Two-stage stochastic programming

17 Two-stage stochastic programming is one of the most widely applied stochastic methods where 18 decisions are made in two different stages. First-stage or here and now decisions must be made before the 19 realization of the random variables. Second-stage or wait-and-see decisions are made after knowing the 20 realization of random variables and depends of the decisions made in first-stage. Two-stage stochastic 21 programming can be formulated as follows:

$22 \max c^{T} x+E\left[\max _{y_{\omega}} q_{\omega}^{T} y_{\omega}\right]$

23 Subject to:

$24 \quad \underline{b} \leq A x \leq \bar{b}$

$25 \underline{h_{\omega}} \leq T_{\omega} x+W_{\omega} y_{\omega} \leq \overline{h_{\omega}}, \forall \omega$

$x \geq 0, y_{\omega} \geq 0, \forall \omega$ 
1 In (13) $c$ is a known vector of the objective function coefficients for the $x$ variables in the first stage,

$2 x$ and $y_{\omega}$ are the first and second-stage variables vectors, respectively, $q_{\omega}$ is the vector of the objective

3 function coefficients for the $y$ variables. In (14) $\underline{b}$ and $\bar{b}$ are respectively the lower and upper bound

4 vectors for the first-stage constraints and $A$ is the known matrix of coefficients for the first-stage

5 constraints. In (15) $\underline{h}_{\omega}$ and $\overline{h_{\omega}}$ are respectively the vectors for the second-stage constraints, while $T_{\omega}$ is

6 the technology matrix and $W_{\omega}$ is the recourse matrix. The two-stage stochastic programming problem

7 formulated from (13) to (16) can be equivalently expressed in the deterministic equivalent problem as

8 follows:

$9 \max _{x, y_{\omega}} c^{T} x+\sum_{\omega}^{\Omega} \rho_{\omega} q_{\omega}^{T} y_{\omega}$

10 Subject to:

$11 \underline{b} \leq A x \leq \bar{b}$

$12 \underline{h_{\omega}} \leq T_{\omega} x+W_{\omega} y_{\omega} \leq \overline{h_{\omega}}, \forall \omega$

$13 x \geq 0, y_{\omega} \geq 0, \forall \omega$

\section{4. Mathematical Formulation}

15 The problem is formulated as a two-stage stochastic programming one, considering uncertainty on 16 wind and PV powers and market prices. The optimal bid is determined by a mixed integer linear programming (MILP) approach, where the hourly bid is the first stage variable and the positive and negative energy deviations are the second stage variables for the disjoint operation. For the joint operation the energy stored, the charged energy and the discharged energy of the energy storage device are also first-stage variables. The uncertainties on wind power and on PV power availabilities are assumed as stochastic and modelled by convenient scenarios. These scenarios are elements of set $\Omega$, which is the set of scenarios for the next day 24 hours. Each scenario $\omega$ is weighted by the probability of occurrence $\pi_{\omega}$.

\subsection{Objective function of disjoint operation}

24 The stochastic MILP formulation of the problems to support the biding strategies in a disjoint assessment of wind power and PV power systems are similar maximization problems respectively as follow: 
$2 \sum_{\omega=1}^{\Omega} \sum_{t=1}^{T} \pi_{\omega}\left(\lambda_{t \omega}^{D} P_{t}^{W}+\lambda_{t \omega}^{D} r_{t \omega}^{+} \Delta_{t \omega}^{W+}-\lambda_{t \omega}^{D} r_{t \omega}^{-} \Delta_{t \omega}^{W-}\right)$

b) PV system

$4 \sum_{\omega=1}^{\Omega} \sum_{t=1}^{T} \pi_{\omega}\left(\lambda_{t \omega}^{D} P_{t}^{P V}+\lambda_{t \omega}^{D} r_{t \omega}^{+} \Delta_{t \omega}^{P V+}-\lambda_{t \omega}^{D} r_{t \omega}^{-} \Delta_{t \omega}^{P V-}\right)$

\section{$5 \quad$ Energy offer constraints}

$60 \leq P_{t}^{W} \leq P^{W \max }, \forall t$

$7 \quad 0 \leq P_{t}^{P V} \leq P^{P V \max }, \forall t$

\section{$8 \quad$ Imbalance constraints}

$9 \Delta_{t \omega}^{W}=P_{t \omega}^{W}-P_{t}^{W}, \forall t, \forall \omega$

$10 \Delta_{t \omega}^{W}=\Delta_{t \omega}^{W+}-\Delta_{t \omega}^{W-}, \forall t, \forall \omega$

$110 \leq \Delta_{t \omega}^{W+} \leq P_{t \omega}^{W} u_{t \omega}^{W}, \forall t, \forall \omega$

$120 \leq \Delta_{t \omega}^{W-} \leq P^{W \max }\left(1-u_{t \omega}^{W}\right), \forall t, \forall \omega$

$13 \Delta_{t \omega}^{P V}=P_{t \omega}^{P V}-P_{t}^{P V}, \forall t, \forall \omega$

$14 \Delta_{t \omega}^{P V}=\Delta_{t \omega}^{P V+}-\Delta_{t \omega}^{P V-}, \forall t, \forall \omega$

$150 \leq \Delta_{t \omega}^{P V+} \leq P_{t \omega}^{P V} u_{t \omega}^{P V}, \forall t, \forall \omega$

$160 \leq \Delta_{t \omega}^{P V-} \leq P^{P V \max }\left(1-u_{t \omega}^{P V}\right), \forall t, \forall \omega$

17 In (23) and (24) the upper bounds on the bid are set to be the maximum capacity, respectively, for wind

18 and PV powers. In (25) to (28) and (29) to (32) the imbalances are decomposed into a difference of non-

19 negative values, i.e., the difference between the positive and the negative imbalances, respectively, for

20 wind power and PV power. In (27), (28) and (31), (32) are respectively imposed for wind power and PV

21 power that the positive imbalances $\Delta_{t \omega}^{W+}, \Delta_{t \omega}^{P V+}$ and the negative imbalances $\Delta_{t \omega}^{W-}, \Delta_{t \omega}^{P V-}$ are non-

22 negative. If the imbalance is negative, the term $\lambda_{t \omega}^{D} r_{t \omega}^{+} \Delta_{t \omega}^{W+}\left(\lambda_{t \omega}^{D} r_{t \omega}^{+} \Delta_{t \omega}^{P V+}\right)$ is null and the term $\lambda_{t \omega}^{D} r_{t \omega}^{-} \Delta_{t \omega}^{W-}$

$23\left(\lambda_{t \omega}^{D} r_{t \omega}^{-} \Delta_{t \omega}^{P V-}\right)$ is subtracted from the revenue assessed in conditions of non-imbalance, $\lambda_{t \omega}^{D} P_{t}^{W}\left(\lambda_{t \omega}^{D} P_{t}^{P V}\right)$. If

24 the system imbalance is positive, the term $\lambda_{t \omega}^{D} r_{t \omega}^{-} \Delta_{t \omega}^{W-}\left(\lambda_{t \omega}^{D} r_{t \omega}^{-} \Delta_{t \omega}^{P V-}\right)$ is null and the term $\lambda_{t \omega}^{D} r_{t \omega}^{+} \Delta_{t \omega}^{W+}$ 
$1\left(\lambda_{t \omega}^{D} r_{t \omega}^{+} \Delta_{t \omega}^{P V+}\right)$ is added to the revenue assessed in conditions of non-imbalance. In (27) and (31) the

2 maximum positive imbalance for each scenario at hour $t$ occurs when no amount of energy is bidded in

3 the day-ahead market, $P_{t}^{W}=0\left(P_{t}^{P V}=0\right)$, but the physical delivering is given by $P_{t \omega}^{W}\left(P_{t \omega}^{P V}\right)$. In $(28)$ and

4 (32) the maximum negative imbalance is the maximum capacity $P^{W \max }$ and $P^{P V \max }$, respectively, for wind 5 power and PV power.

6

74.2 Objective function

8 The final goal is to find a single optimal bid in day-ahead market that includes wind power, PV power 9 generations and the power of the energy storage. The stochastic MILP formulation for joint operation of 10 wind power, PV power and the power of energy storage is specified by the maximization of the objective 11 function given as follows:

$12 \sum_{\omega=1}^{\Omega} \sum_{t=1}^{T} \pi_{\omega}\left(\lambda_{t \omega}^{D} P_{t}+\lambda_{t \omega}^{D} r_{t \omega}^{+} \Delta_{t \omega}^{+}-\lambda_{t \omega}^{D} r_{t \omega}^{-} \Delta_{t \omega}^{-}\right)$

13 General constraints

14 a) Energy offer constraint

$150 \leq P_{t} \leq P^{W \text { max }}+P^{P V \max }+P_{t}^{D e \max }$

16 b) Output power of combined wind power, PV power and energy storage device

$17 P_{t \omega}=P_{t \omega}^{W}+P_{t \omega}^{P V}-P_{t}^{\text {Chbat }}+P_{t}^{\text {Debat }}$

18 Imbalance constraints

$19 \Delta_{t \omega}=P_{t \omega}-P_{t}, \forall t, \forall \omega$

$20 \Delta_{t \omega}=\Delta_{t \omega}^{+}-\Delta_{t \omega}^{-}, \forall t, \forall \omega$

$210 \leq \Delta_{t \omega}^{+} \leq P_{t \omega} u_{t \omega}, \forall t, \forall \omega$

$220 \leq \Delta_{t \omega}^{-} \leq\left(P^{W \max }+P^{P V \max }+P^{D e \max }\right)\left(1-u_{t \omega}\right), \forall t, \forall \omega$

23 Constraints of energy storage device

a) Energy storage equation

$E_{t}^{\text {bat }}=E_{t-1}^{\text {bat }}+\eta^{\text {Chbat }} P_{t}^{\text {Chbat }}-\frac{1}{\eta^{\text {Debat }}} P_{t}^{\text {Debat }}$ 
$10 \leq E_{t}^{\text {bat }} \leq E^{\text {bat } \max }$

2 c) Storage power limits

$30 \leq P_{t}^{\text {Chbat }} \leq P_{t}^{\text {Chbat max }} k_{t}$

$4 \quad 0 \leq P_{t}^{\text {Debat }} \leq P_{t}^{\text {Debat } \max }\left(1-k_{t}\right)$

5 In (40) to (43) a vanadium redox flow battery type is considered, (41) imposes the bounds on the state of

6 charge, assuming a possible total discharge of the battery, i.e., a null depth of discharge. But, if the type

7 of battery used imposes a non-null depth of discharge, the lower bound of (41) should be considered with

8 the state of charge value of energy associated with the depth of discharge. A single line diagram of the

9 wind, PV and energy storage device system is shown in Fig. 1.

"See Fig. 1 at the end of the manuscript".

11 In Fig. 1 VRFB means vanadium redox flow battery and BMS means battery management system. A 12 schematic representation for disjoint operation and for joint operation having energy storage device, 13 corresponding respectively to uncoordinated and coordinated bid strategies are shown in Fig. 2.

"See Fig. 2 at the end of the manuscript".

The procedure of the coordinated bid strategy is shown in Fig. 3.

"See Fig. 3 at the end of the manuscript".

17 The procedure presented in Fig. 3 is divided in 3 blocks. Block 1 shows the scenario generation procedure where the scenarios are obtained via wind power conversion and solar power conversion using historical data of wind speed and solar irradiance, respectively. Market price and imbalance price scenarios are obtained with historical data from the Iberian Electricity Market. In Block 2 after the scenarios are available and using data from rated power of the wind system, PV system and the specifications of the energy storage device, the formulation presented in this paper is solved in the software GAMS, with the solver CPLEX. The decision maker uses a two-stage stochastic optimization, where the first-stage variables are the optimal hourly bids for the 24 hours and the energy flow in the batteries while the second stage variables are the energy imbalance (negative and positive). Note that the problem is formulated as a stochastic MILP approach. Block 3 is for the results obtained that are exported to an EXCEL file. When this process is concluded the decision maker obtain the optimal hourly bids to present 
1 in the day-ahead market and an approximation of the expected profit of selling this energy in the

2 electricity markets.

\section{5. Case Study}

4 The bidding is on an hourly basis in a day-ahead market using historical data of scenarios from 510 days of June 2015 of the Iberian Peninsula [36]. Installed capacity for the wind farm and the PV farm 6 are respectively $100 \mathrm{MW}$ and $50 \mathrm{MW}$. Energy storage device charging and discharging efficiencies are $780 \%$ and $95 \%$, respectively. The case study involves: Case_1, only with wind power; Case_2, only with 8 PV power; and Case_3, joint operation of wind with PV powers having energy storage device. The 9 scenarios for the day-ahead market prices (blue line) and the day-ahead average market prices (black line) are shown in Fig. 4.

Fig. 4 shows that the best prices are around $13 \mathrm{~h}$. Also, the lower average price is 45 Euros/MWh, so energy storage device discharge is expected for at least an average price of 59 Euros/MWh and only few scenarios have prices above this one and those prices are around $13 \mathrm{~h}$. So, from the efficiency of charging discharging is concluded that the storing is anticipated as having a value above what the impact is marginal. The scenarios for $r_{t}^{+}$(blue line) and the average price of $r_{t}^{+}$scenarios (black line) are shown in Fig. 5.

The scenarios for $r_{t}^{-}$(blue line) and the average price of $r_{t}^{-}$scenarios (black line) are shown in Fig. 6.

Fig. 5 and Fig. 6 shows that the positive imbalance is in average less penalized from $3 \mathrm{~h}$ to $10 \mathrm{~h}$ and the negative imbalance is in average more penalized from $0 \mathrm{~h}$ to $10 \mathrm{~h}$ and from $15 \mathrm{~h}$ to $24 \mathrm{~h}$, respectively. So, schedules of power eventually lending to bidding with positive imbalance are favoured from $3 \mathrm{~h}$ to $10 \mathrm{~h}$. The negative imbalance is in average less penalized from $10 \mathrm{~h}$ to $15 \mathrm{~h}$, while the positive one is in average more penalized around $13 \mathrm{~h}$ and around $19 \mathrm{~h}$. So, scenarios of power eventually lending to bidding with negative imbalance are favoured around $13 \mathrm{~h}$ and $19 \mathrm{~h}$. The case study is solved by GAMS/CPLEX. The CPU time, number of equations, continuous variables and integer variables are shown in Table 1. 
1 Table 1 allows concluding that the CPU time for computing the joint bid is augmented due to the number

2 of scenarios given by the product of the number of the wind power by the number of PV power scenarios.

3 In addition, the energy storage device requires the inclusion of integer variables for controlling the device.

4 Although the number of equations, continuous variables and integer ones is about ten times greater the

5 CPU time is increased about two times and is not relevant in what regards an information management

6 system for supporting decision of bidding in a day-ahead market.

$7 \quad 5.1-$ Case_1

8 Only the wind farm is considered in operation and without energy storage. The wind power scenarios 9 (blue line) and the average power scenario (black line) are shown in Fig. 7.

"See Fig. 7 at the end of the manuscript".

11 Fig. 7 shows that the wind power has a considerable uncertainty with an average values almost in the 12 power range of $40 \pm 10 \mathrm{MW}$. Also, in order to consider unforeseen events, as for instance failure of 13 equipment, in some of the scenarios the available wind power may have a reduction in comparison with 14 the accessible one. Case_1 uses the data shown in Fig. 4, Fig. 5, Fig. 6 and Fig. 7 and the results are obtained using the formulation for wind system with equations (21), (23) and from (25) to (28). The optimal hourly bid is shown in Fig. 8 .

"See Fig. 8 at the end of the manuscript".

Fig. 8 shows that the higher levels of bid above 40 MW occur in hours of likely high market prices. As negative imbalance is favourable around $13 \mathrm{~h}$ and $19 \mathrm{~h}$, scenarios with high power are favoured at those hours. Also is shown that at $0 \mathrm{~h}$ the level of the bid is almost the average of the available power, because at this hour the imbalances price ratios in average have almost identical consequences, $20 \%$ out. $5.2-$ Case_2

Only the PV system is considered in operation and without energy storage. The PV power scenarios are the typical ones due to the solar typical period of irradiance in June (blue line) and are shown with the average PV power (black line) in Fig. 9.

"See Fig. 9 at the end of the manuscript".

27 A comparison between Fig. 7 and Fig. 9 allows concluding that the PV power has lesser uncertainty than 28 the wind power. Obviously, PV power has no uncertainty from $0 \mathrm{~h}$ to $5 \mathrm{~h}$ and from $21 \mathrm{~h}$ to $24 \mathrm{~h}$. In order 
1 to consider unforeseen events, as for instance failure of equipment, in some of the scenarios the power

2 may have a reduction in comparison with the accessible one. Case_2 uses data shown in Fig. 4, Fig. 5,

3 Fig. 6 and Fig. 9 and the results are obtained using the formulation for PV system with equations (22),

4 (24) and from (29) to (32). The optimal hourly bid is shown in Fig. 10.

"See Fig. 10 at the end of the manuscript".

6 Fig. 10 shows as expected that the bid follows the average power except at around $13 \mathrm{~h}$ and $19 \mathrm{~h}$,

7 favourable for negative imbalance and with likely high market prices, where the scenarios of higher

8 power are expected to be followed as stated in Case_1. The transition from average power to scenarios of

9 higher power is clear at $11 \mathrm{~h}$ with more than $40 \mathrm{MWh}$ of bid, while the average power has a lesser value.

$10 \quad 5.3-$ Case_3

11 Joint operation of the wind farm, PV system and the energy storage device in order to submit a joint 12 bid. Case_3 uses data shown in Fig. 4, Fig. 5, Fig. 6, Fig. 7 and Fig. 9 and the results are obtained using 13 the formulation for the joint operation from equation (33) to (43). The optimal hourly bids for the uncoordinated (blue) having an energy storage device rated power is $10 \mathrm{MW}$ and for the coordinated (brown) operations are shown in Fig. 11.

"See Fig. 11 at the end of the manuscript".

Fig. 11 shows that the uncoordinated configuration allows to present higher bids between $11 \mathrm{~h}$ and $15 \mathrm{~h}$. If the actual production is less than the bid presented in the day-ahead market implies that the power producer is subject to the imbalance procedure and should pay a price higher than the day-ahead market price. So, taken in account the scenarios of day-ahead market prices and imbalance prices, Fig. 11 shows that is better to present a moderate bid between $11 \mathrm{~h}$ and $15 \mathrm{~h}$. Fig. 11 also shows as expected equal operations from $0 \mathrm{~h}$ to $3 \mathrm{~h}$ and $21 \mathrm{~h}$ to $24 \mathrm{~h}$ as the available $\mathrm{PV}$ power is null and no charge or discharge of the store device is called in these hours, see Fig. 9 and the following two figures. The amount of energy stored in the energy storage device given by (40) (green line) and the average market price (blue line) giving a qualitative tendency of change of price are shown in Fig. 12.

"See Fig. 12 at the end of the manuscript".

Fig. 12 shows that although of the $24 \%$ loss of energy due to the charging and discharging cycle of the storage device, storing is called for optimal bidding. The energy storage device by the tendency of change of price is as expected charging in $4 \mathrm{~h}$ and $5 \mathrm{~h}$, having the tendency for likely low market prices and 
1 favourable for positive imbalance, being the charge more intensive in $5 \mathrm{~h}$, having the tendency for lowest

2 likely price. The energy stored is hold until the tendency of favourable price condition for discharging

3 happen at $13 \mathrm{~h}$. If the problem is treated as a deterministic one, the market prices has only influence on

4 the decision of charging and discharging the energy storage device as long as the available power is not

5 greater than the maximum values allowed for delivering energy. So, for Case_3 is expected that the

6 market prices have a significant influence on decision of charging and discharging and in the respectively

7 hours, but some influence is expected on the schedule of the farms production in other hours. The energy

8 discharged (green line) and average market price (blue line) are shown in Fig. 13.

"See Fig. 13 at the end of the manuscript".

10 Fig. 12 and Fig. 13 show that the energy storage favours a convenient accommodation of energy, i.e., 11 storing and delaying conveniently the use of energy to a more profitable hour: charging in $4 \mathrm{~h}$ and $5 \mathrm{~h}$ and releasing at $13 \mathrm{~h}$. The charging energy is taken from the wind power and accounts for the fact of the schedule in Fig. 11 for the coordinated operation is less than the one for the uncoordinated operation in those two hour. So, if there is no storage device available, then the schedules at $4 \mathrm{~h}$ and at $5 \mathrm{~h}$ in Fig. 11 are also the same. The expected energy traded and the expected profits for Case_1, Case_2 and for Case_3 are obtained applying the formulation from (21) to (32) for the wind and PV systems and the formulation from (33) to (43) for the joint operation of wind and PV systems having energy storage devices. These expected energy trades and the expected profits are shown in Table 2.

"See Table 2 at the end of the manuscript".

Table 2 exposes that the expected energy traded and the total expected profit of uncoordinated operation are respectively 1,246 MWh and 66,882 $€$, while for coordinated operation having energy store device are respectively $1,183 \mathrm{MWh}$ and $67,355 €$. So, although the expected energy traded is decremented of $63 \mathrm{MWh}$ the profit given by (33) increases about $471 €$, i.e., about $0.7 \%$ per day with the joint bid relatively to the disjoint one. The expected profits for Case_3 in function of the rated power of the energy storage device, starting at $1 \mathrm{MW}$ and from $5 \mathrm{MW}$ to $20 \mathrm{MW}$ by steps of $5 \mathrm{MW}$, applying (33) to (43), are shown in Table 3. 
1 Table 3 allows to conclude that increasing the power of the storage device from $5 \mathrm{MW}$ to $20 \mathrm{MW}$ only

2 allows an increase on expected profit of about $14 €$ per each $5 \mathrm{MW}$ of added power. In the deterministic

3 version of the problem of electric energy production having energy store device the effect of the day-

4 ahead price is accountable for the schedule of the levels and hours of charging and of discharging the

5 energy storage device. But in the stochastic version the interaction effect of the scenarios of the day-ahead

6 market price with scenarios of the wind power and of the PV power is accountable for the schedule of the

7 levels and hours of charging and of discharging the energy storage device and obvious has importance in

8 the other hours. The sum of absolute values of the imbalances for Case_1, Case_2 and Case_3 having a

9 rated power of $10 \mathrm{MW}$ for the energy store device are shown in Table 4.

"See Table 4 at the end of the manuscript".

11 Table 4 presents the absolute value of the imbalance, which means the sum of the negative energy imbalance (power producer generation is less than the energy accepted for trading in day-ahead market)

13 with the positive energy imbalance (power producer generation is greater than the energy accepted for trading in day-ahead market). These absolute values show the stochastic impact of variable nature of wind and PV powers and the convenient accommodation of the coordination: the sum of the imbalance of Case_1 with Case_2, $318 \mathrm{MWh}$, is greater than the imbalance of Case_3, $191 \mathrm{MWh}$. This imbalance reduction is an advantage of the coordinated operation regarding the ability to mitigate the impact of uncertainties in the energy imbalance comparatively with the uncoordinated one.

Also, included in Case_3 in order to investigate the influence of the uncertainty of the wind power and of the PV power are the following simulations subjected to the day-ahead average market prices and imbalance price ratios scenarios for the following conditions of available power: wind power scenarios with PV power average scenario; wind power average scenario with PV power scenarios; wind power scenarios with PV power scenarios. The optimal hourly bids of these simulations with the day-ahead average market prices are shown in Fig. 14.

"See Fig. 14 at the end of the manuscript".

26 Fig. 14 shows the following bids: at blue, when the PV power has non-uncertainty and has available the average power of the power scenarios; at green, when the wind power has non-uncertainty and has available the average power of the power scenarios; and at brown, when the power scenarios are 
1 considered. A comparison between the blue and brown bids allows to conclude that for all hours from

$211 \mathrm{~h}$ to $16 \mathrm{~h}$ and $18 \mathrm{~h}, 20 \mathrm{~h}$, favourable for negative imbalance, the scenarios with high level of PV power

3 are chosen for biding as expected and implied by the conclusions of Case_2. A comparison between the

4 green and brown bids allows to conclude that for all hours except $12 \mathrm{~h}, 14 \mathrm{~h}$ and $19 \mathrm{~h}$, the scenarios with

5 high level the wind power are chosen as expected and implied by the conclusions of Case_1. The

6 exceptions are in hours $13 \mathrm{~h}$ although favourable for negative imbalance the discharge of energy of the

7 store device is favourable due to the likely high day-ahead market prices, and in $19 \mathrm{~h}$ favourable for

8 negative imbalance. Also, at the $0 \mathrm{~h}$ the bids are shown to be all identical to the one with average wind

9 power, again as expected and implied by a conclusion of Case_1. Furthermore, the bids at blue and at

10 brown are equal from $0 \mathrm{~h}$ to almost $6 \mathrm{~h}$ and $21 \mathrm{~h}$ to $24 \mathrm{~h}$ as a consequence of a null PV power at those

11 hours. As a conclusion, both uncertainties described by the scenarios and the associated probabilities are

12 processed by the imbalance price ratios to influence the levels of the bid. This influence has a greater

13 impact than the uncertainty in the day-ahead market prices.

14

15

\section{Conclusions}

16 A support information management system is addressed for the problem of a joint bidding in a day-

17 ahead market for a producer having wind power with PV power and a vanadium redox flow battery for 18 energy storage. Which is one of the most promising storage technology for application at power plants to 19 compensate the fluctuations of wind and photovoltaic power plants. The problem is formulated as a 20 stochastic optimization problem addressed as MILP problem. In general, stochastic MILP is a suitable 21 approach to address uncertainty as long as a linear formulation is an acceptable modelling either with continuous variables or integer ones. Particularly, wind power, PV power systems and energy storage

23 device operations can be treated by this modelling, having the wind power, PV power, market prices and 24 imbalance ratio prices described by a set of scenarios.

25 The joint bidding is envisaged as a favourable one when the mismatch of uncertainty due to the wind power and the PV power is partial disabled by one another and an energy storage device allows the

27 flexibility of storing energy and discharging at hours of convenient day-ahead market prices. Then this 28 bidding is envisaged as having some interest in day-ahead market, reducing energy imbalance and 29 augmenting the revenue. But, although depending in the particular scenarios at simulation and 30 considering that at least during one third of the day the PV power has a null value, the revenue is not 
1 expected as having to have a necessary large augmentation. In one third of the hours of the day the PV

2 power is with non-uncertainty but with a null value. So, the uncertainty due to the wind power is not

3 disabled in those hours and in some of other hours the disabled depends on the scenarios of power and

4 prices. So, as long as there are not enough favourable prices to store significate amounts of energy, one

5 should not expect a significant augmentation on revenue as shown by the illustrative case study. The

6 market prices have a significate influence on the decision of charging and discharging the energy storage

7 and lesser influence on the schedule of the production in other hours.

8 The CPU time for the joint operation assessment of bid has an augmentation, due to the inclusion of

9 the wind power scenarios and PV power scenarios in the same problem addressed as a joint one, but this

10 augmentation on the CPU time is not relevant in what regards an information management system for

11 supporting decision of bidding in a day-ahead market.

12

\section{Acknowledgment}

15 This work is funded by Portuguese Funds through the Foundation for Science and Technology-FCT 16 under the project LAETA 2015-2020, reference UID/EMS/50022/2013 and by Millennium BCP 17 Foundation.

\section{References}

20 [1] Hickey, E.A., Carlson, J.L., 2010. An analysis of trends in restructuring of electricity markets. The Electricity Journal 23(5), 47-56.

[2] Laia, R., Pousinho, H.M.I., Melício, R., Mendes, V.M.F., 2015. Self-scheduling and bidding strategies of thermal units with stochastic emission constraints. Energy Conversion and Management 89, 975-984.

[3] Fialho, L., Melicio, R., Mendes, V.M.F., Viana, S., Rodrigues, C., Estanqueiro, A., 2014. A simulation of integrated photovoltaic conversion into electric grid. Solar Energy 110, 578-594.

[4] Azizipanah-Abarghooee, R., Niknam, T., Bina, M.A., Zare, M., 2015. Coordination of combined heat and power-thermal-wind-photovoltaic units in economic load dispatch using chance-constrained and jointly distributed random variables methods. Energy 79, 50-67.

[5] Rodrigues, E.M.G., Osório, G.J., Godina, R., Bizuayehu, A.W., Lujano-Rojas, J.M., Matias, J.C.O., Catalão, J.P.S., 2015. Modelling and sizing of NaS (sodium sulfur) battery energy storage system for extending wind power performance in Crete Island. Energy 90, 1606-1617. 
[6] Barbour, E., Wilson, I.A.G., Radcliffe, J., Ding, Y., Li, Y., 2016. A review of pumped hydro energy storage development in significant international electricity markets. Renewable and Sustainable Energy Reviews 61, $421-432$.

[7] REN21. Renewables 2015 global status report: 2015. Available at: http://www.ren21.net/.

[8] Ueckerdt, F., Brecha, R., Luderer, G., 2015. Analyzing major challenges of wind and solar variability in power systems. Renewable Energy 81, 1-10.

[9] Wang, T., Gong, Y., Jiang, C, 2014. A review on promoting share of renewable energy by green-trading mechanisms in power system. Renewable and Sustainable Energy Reviews 40, 923-929.

[10] Bhuiyan, M.M.H., Asgar, M.A., 2003. Sizing of a stand-alone photovoltaic power system at Dhaka. Renewable Energy 28(6), 929-938.

[11] Denholm, P., Ela, E., Kirby, B., Milligan, M., 2010. The role of energy storage with renewable electricity generation, National Renewable Energy Laboratory, Colorado, USA.

[12] Beaudin, M., Zareipour, H., Schellenberglabe, A., Rosehart, W., 2010. Energy storage for mitigating the variability of renewable electricity sources: an updated review. Energy for Sustainable Development 14(4), $302-314$.

[13] Steinke, F., Wolfrum, P., Hoffmann, C., 2013. Grid vs. storage in a $100 \%$ renewable Europe. Renewable Energy 50, 826-832.

[14] Divya, K.C., Østergaard, J., 2009. Battery energy storage technology for power systems-an overview. Electric Power Systems Research 79(4), 511-520.

[15] Zebarjadi, M., Askarzadeh, A., 2016. Optimization of a reliable grid-connected PV-based power plant with/without energy storage system by a heuristic approach. Solar Energy 125, 12-21.

[16] Arribas, B.N., Melicio, R., Teixeira, J.G., Mendes, V.M.F., 2016. Vanadium redox flow battery storage system linked to the electric grid. In: Proc. International Conference on Renewable Energies and Power Quality ICREPQ 2016, Madrid, Spain, 1-6.

[17] Shrestha, G.B., Kokharel, B.K., Lie, T.T., Fleten, S.-E., 2005. Medium term power planning with bilateral contracts. IEEE Transactions on Power Systems 20(2), 627-633.

[18] Osório, G.J., Rodrigues, E.M.G., Lujano-Rojas, J.M., Matias, J.C.O, Catalão, J.P.S., 2015. New control strategy for the weekly scheduling of insular power systems with a battery energy storage system. Applied Energy 154, 459-470.

[19] Giannitrapani, A., Paoletti, S., Vicino A, Zarrilli, D., 2014. Bidding strategies for renewable energy generation with non stationary statistics. In: Proc. 19th IFAC World Congress, Cape Town, South Africa, 10784-10789.

[20] Gomes, I.L.R., Pousinho, H.M.I., Melício, R., Mendes, V.M.F., 2016. Bidding and optimization strategies for wind-pv systems in electricity markets assisted by CPS. Energy Procedia 106, 111-121.

[21] Notton, G., Diaf, S., Stoyanov, L., 2011. Hybrid photovoltaic/wind energy systems for remote locations. Energy Procedia 6, 666-677.

[22] Angarita, J.M., Usaola, J.G., 2007. Combining hydro-generation and wind energy: biddings and operation on electricity spot markets. Electric Power Systems Research 77(5-6), 393-400.

[23] Cruz, P., Pousinho, H.M.I., Melício, R., Mendes, V.M.F., 2014. Optimal coordination on wind-pumped-hydro operation. Procedia Technology 17, 445-451.

[24] Parastegari, M., Hooshmand, R.-A., Khodabakhshian, A., Zare, A.-H., 2015. Joint operation of a wind farm, photovoltaic, pump-storage and energy storage device in energy and reserve markets. International Journal of Electrical Power \& Energy Systems 64, 275-284. 
[25] Jerez, S., Trigo, R.M., Sarsa, A., Lorente-Plazas, R., pozo-Vásquez, D., Montávez, J.P., 2013. Spatio-temporal complementarity between solar and wind power in Iberian Peninsula. Energy Procedia 40, 48-57.

[26] González-Garcia, J., Muela, R.M.R., Santos, L.M., González, A.M., 2008. Stochastic joint optimization of wind generation and pumped-storage units in an electricity market. IEEE Transaction on Power Systems 23(2),460468.

[27] Angarita, J.L., Usaola, J., Martínez-Crespo, J., 2009. Combined hydro-wind generation bids in a pool-based electricity market. Electric Power Systems Research 79(7), 1038-1046.

[28] Sundararagavan, S., Baker, E., 2012. Evaluating energy storage technologies for wind power integration. Solar Energy 86(9), 2707-2717.

[29] Matevosyan, J., Söder, L., 2006. Minimization of imbalance cost trading wind power on the short-term power market. IEEE Transactions on Power Systems 21(3), 1396-1404.

[30] Hedman, K.W., Sheble, G.B., 2006. Comparing hedging methods for wind power: using pumped storage hydro units vs. options purchasing. In: Proc. International Conference on Probabilistic Methods Applied to Power Systems - PMAPS 2006, Stockholm, Sweden, 1-6.

[31] Pousinho, H.M.I., Mendes, V.M.F., Catalão, J.P.S., 2010. Investigation on the development of bidding strategies for a wind farm owner. International Review of Electrical Engineering 5(3), 1324-1329.

[32] Laia, R., Pousinho, H.M.I., Melício, R., Mendes, V.M.F., 2016. Bidding strategy of wind-thermal energy producers. Renewable Energy 99, 673-681.

[33] Seixas, M., Melício, R., Mendes, V.M.F, 2016. Offshore wind energy system with DC transmission discrete mass: modeling and simulation. Electric Power Components and Systems 44(20), 2271-2284.

[34] Aktarujjaman, M., Kashem, M.A., Negnevitsky, M., Ledwich, G, 2006. Black start with DEIG based distributed generation after major emergencies. In: Proc. IEEE Power Electronics, Drives and Energy Systems for Industrial Growth, New Delhi, India, December, pp. 1-6. 
$1 \quad$ Figure captions

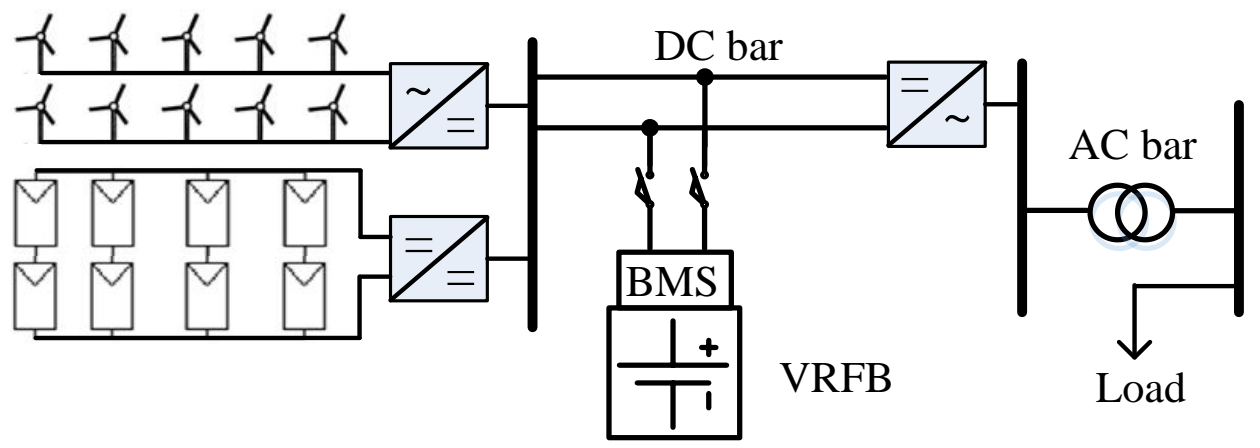

3 Fig. 1. Single line diagram of the wind, PV and energy storage device system.

4
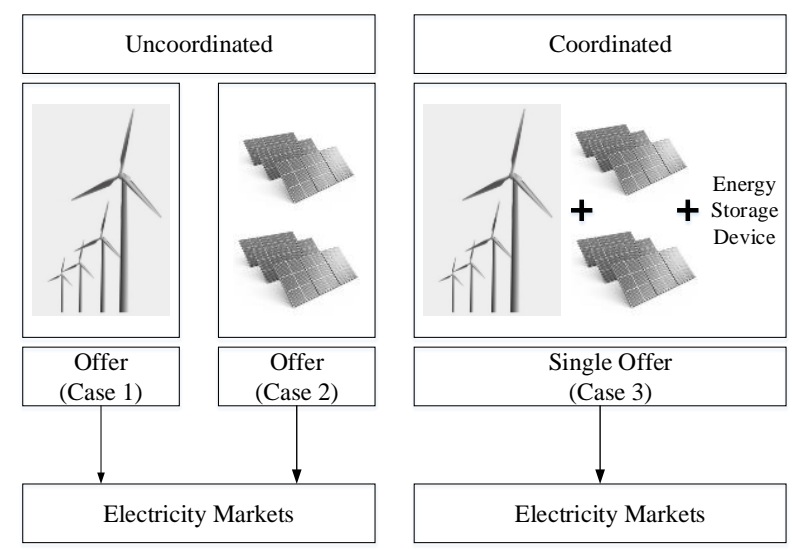

6

Fig. 2. Representation of uncoordinated and coordinated bid strategies. 


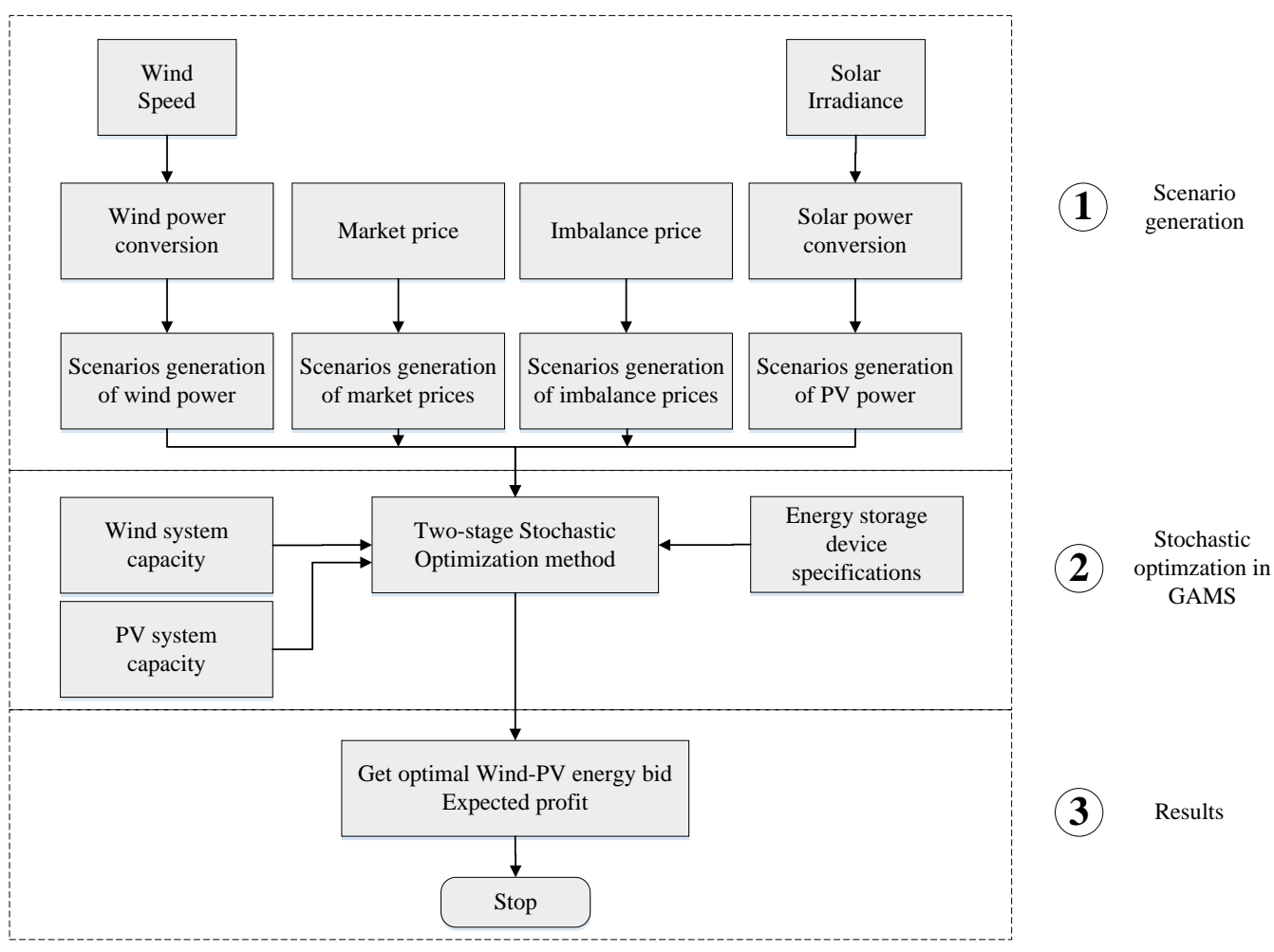

2 Fig. 3. Procedure for coordinated bid strategy.

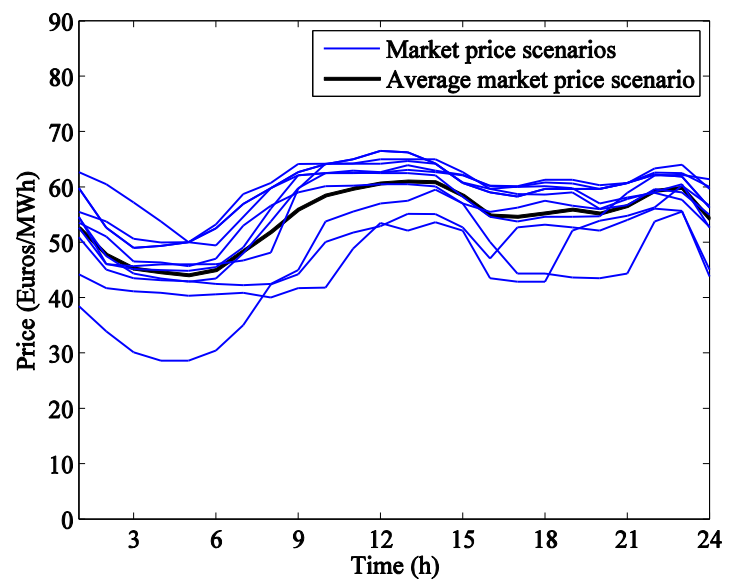

Fig. 4. Day-ahed market prices (blue), average market prices (black). 


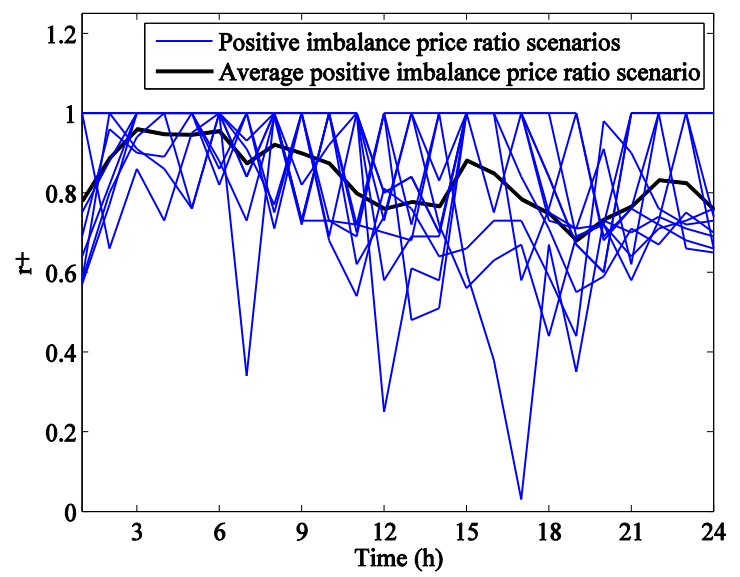

Fig. 5. Positive imbalance price ratios (blue), average positive imbalance price (black).

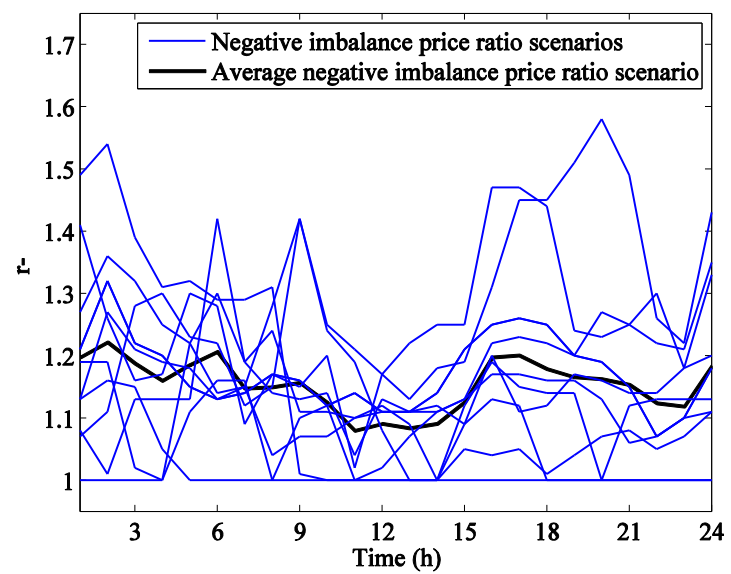

5 Fig. 6. Negative imbalance price ratios (blue), average negative imbalance price (black).

6

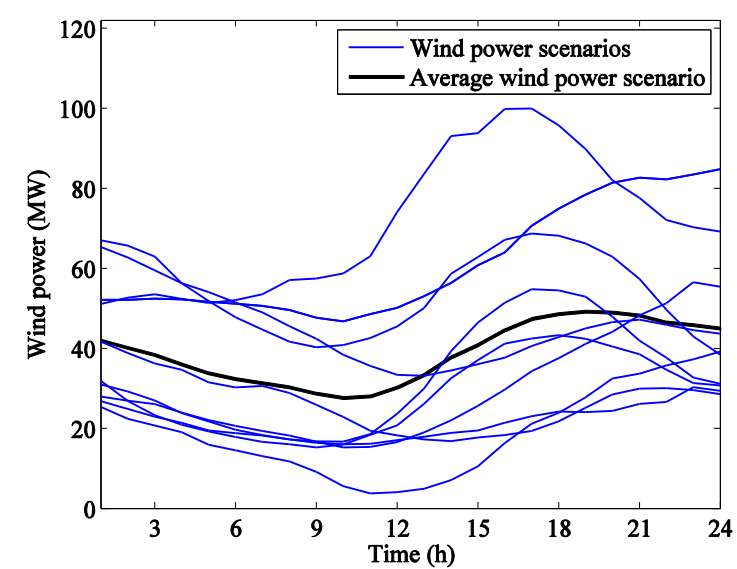

$8 \quad$ Fig. 7. Wind power (blue), average wind power (black). 


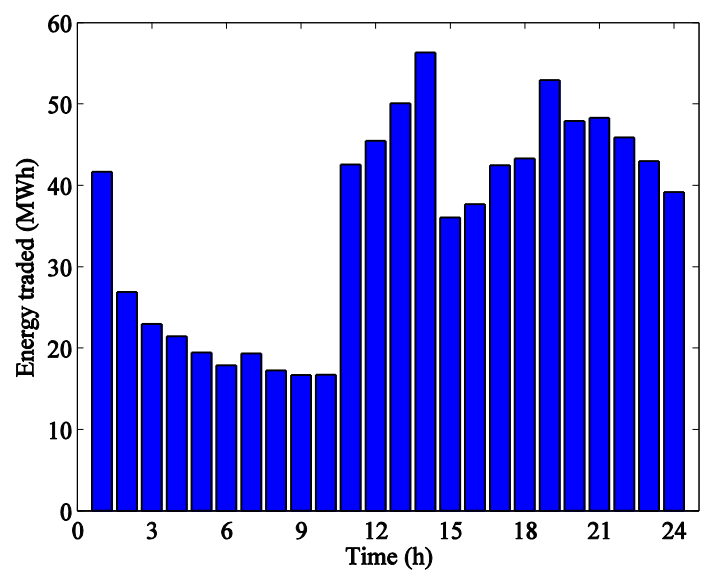

2 Fig. 8. Optimal hourly bid for the wind power.

3

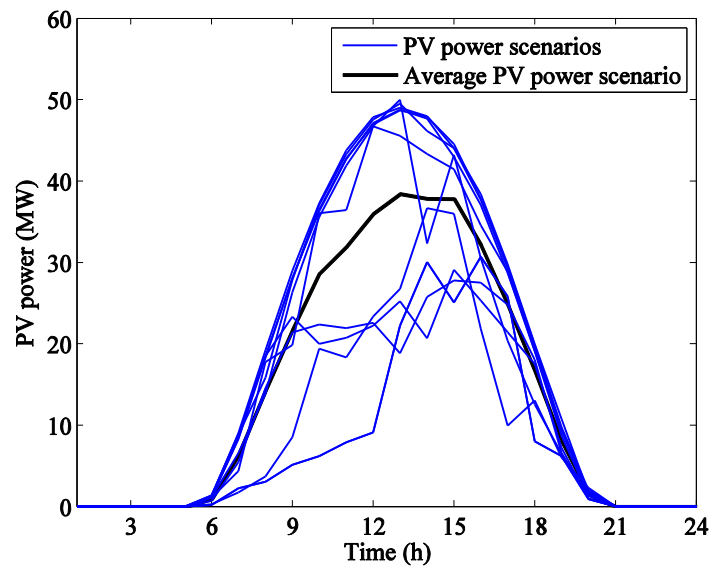

4
5

Fig. 9. PV power (blue), average PV power (black).

6

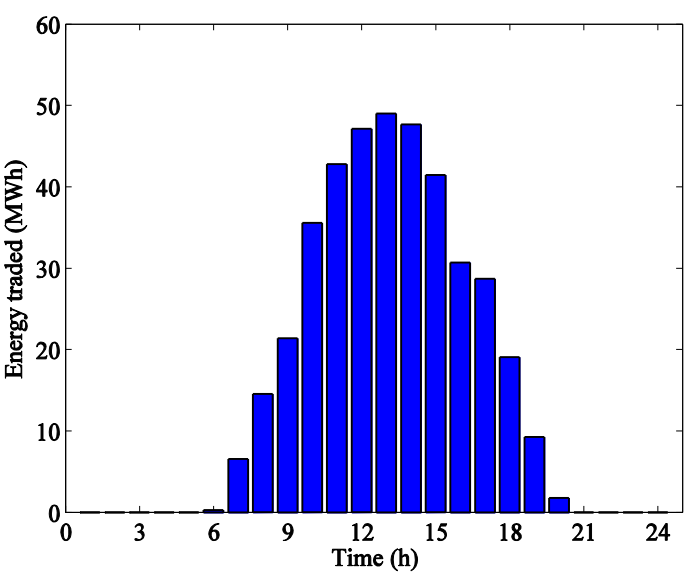

8 Fig. 10. Optimal hourly bid for the PV power. 


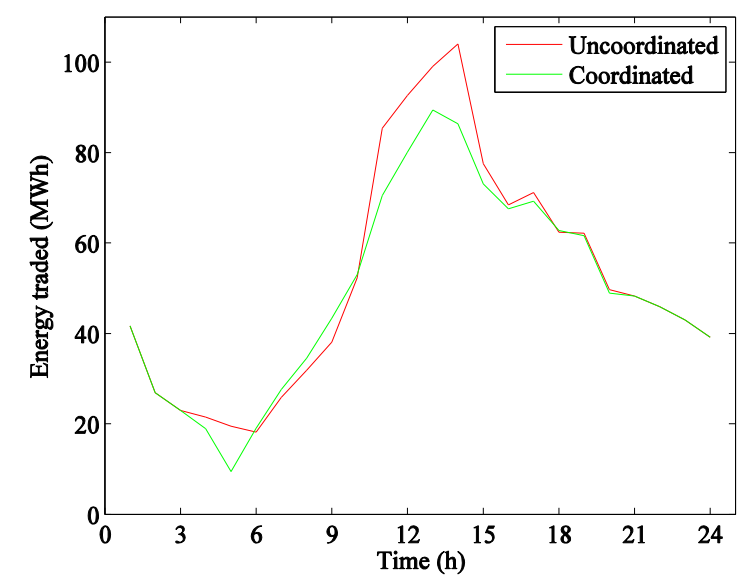

2 Fig. 11. Optimal hourly bids uncoordinated (red), coordinated (green).

3

4

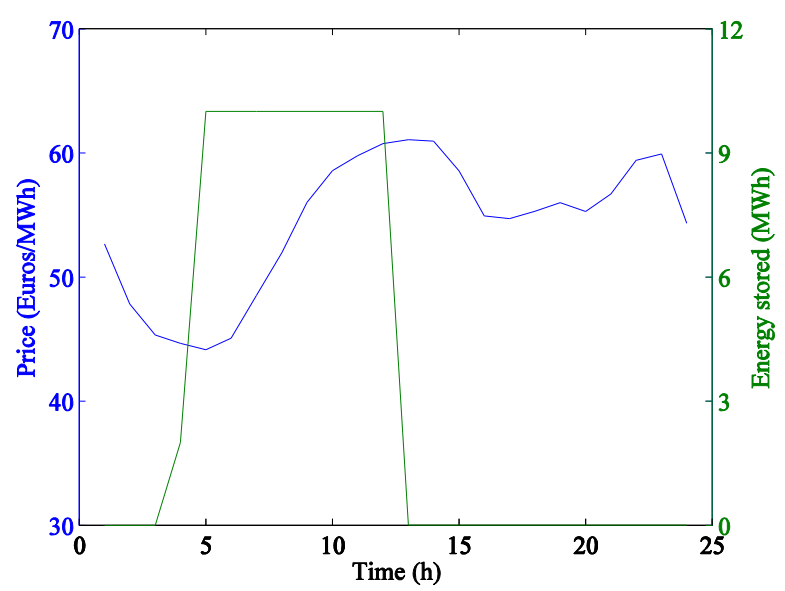

5 Fig. 12. Energy stored (green), average market price (blue).

6

7

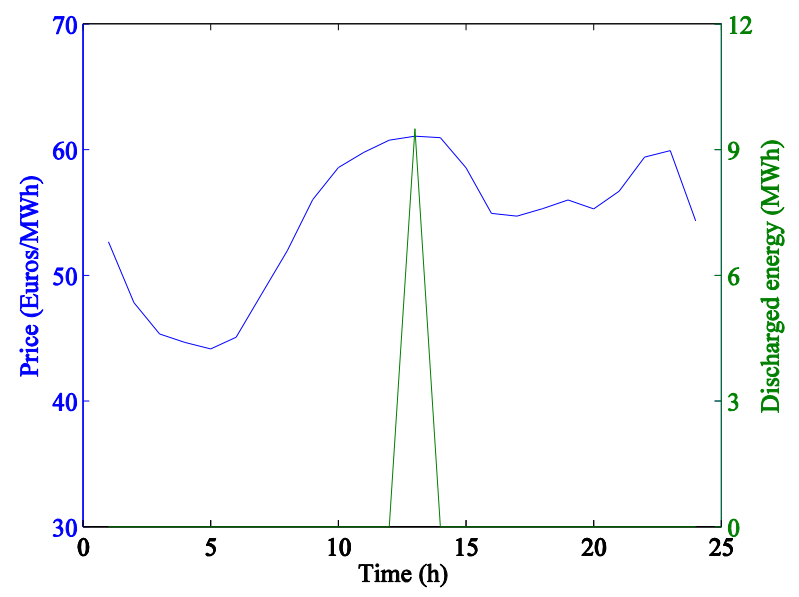

8 Fig. 13. Energy discharged (green), average market price (blue). 


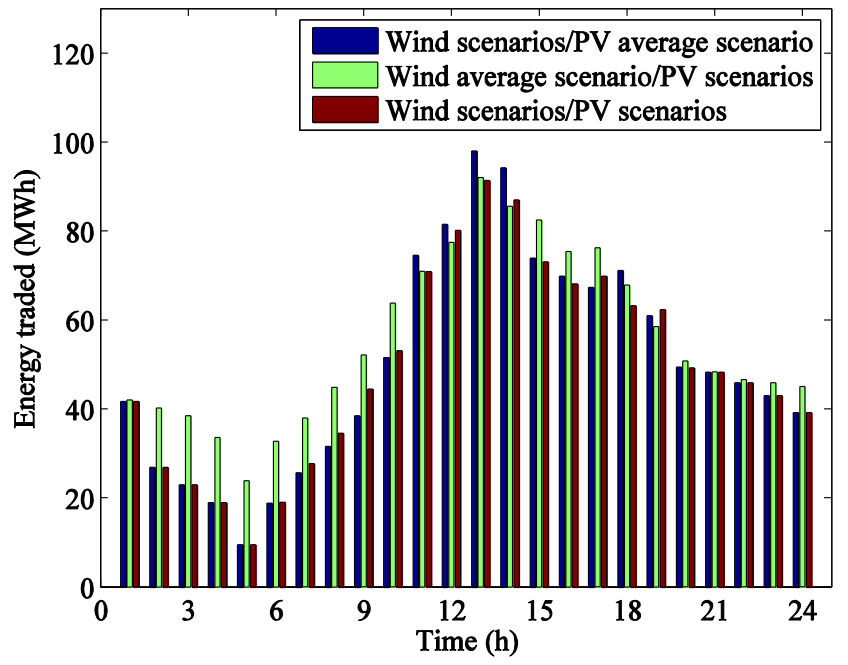

3 Fig. 14. Optimal hourly bid for average day-ahead market prices.

4

5

6

7

8

9

10

11

12

13

14

15

16

17

18

19

20

21

22

23 


\section{Tables}

2

3

4

5

6 Table 1

7 Case studies characteristics

\begin{tabular}{rcc}
\hline$\#$ & Disjoint & Joint \\
\hline CPLEX 12.1 CPU time(s) & 6 & 11 \\
\hline Number of equations & 24,721 & 247,273 \\
\hline Continuous variables & 24,745 & 247,321 \\
\hline Integer variables & 240 & 2,424
\end{tabular}

8

9

10

11

Table 2

12 Energy traded and profit

\begin{tabular}{ccc}
\hline$\#$ & $\begin{array}{c}\text { Energy traded } \\
(\mathrm{MWh})\end{array}$ & $\begin{array}{c}\text { Profit } \\
(€)\end{array}$ \\
\hline Case_1 & 851 & 47,914 \\
\hline Case_2 & 395 & 18,968 \\
\hline Case_3 & 1,183 & 67,355
\end{tabular}

13

14

15

16

17

18

19

20

21

22

23

24 
Table 3

Case_3 profit in function of the rated power of energy storage

\begin{tabular}{cc}
\hline $\begin{array}{c}\text { Power storage } \\
(\mathrm{MW})\end{array}$ & $\begin{array}{c}\text { Profit } \\
(€)\end{array}$ \\
\hline 1 & 67,330 \\
\hline 5 & 67,341 \\
\hline 10 & 67,355 \\
\hline 15 & 67,368 \\
\hline 20 & 67,382 \\
\hline
\end{tabular}

4

5

6

7

8 Table 4

9 Total absolute energy imbalance

\begin{tabular}{cc}
\hline$\#$ & $\begin{array}{c}\text { Energy imbalance } \\
(\text { MWh })\end{array}$ \\
\hline Case_1 & 247 \\
\hline Case_2 & 71 \\
\hline Case_3 & 191 \\
\hline
\end{tabular}

10 